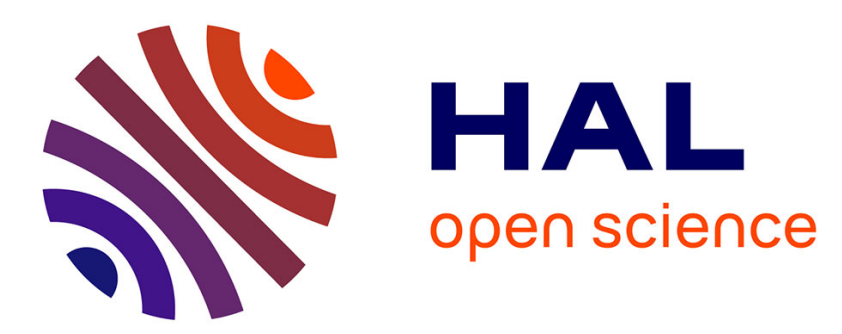

\title{
Articular-surface-based automatic anatomical coordinate systems for the knee bones
}

Jean-Baptiste Renault, Gaëtan Aüllo-Rasser, Mathias Donnez, Sebastien

Parratte, Patrick Chabrand

\section{- To cite this version:}

Jean-Baptiste Renault, Gaëtan Aüllo-Rasser, Mathias Donnez, Sebastien Parratte, Patrick Chabrand. Articular-surface-based automatic anatomical coordinate systems for the knee bones. Journal of Biomechanics, In press, 10.1016/j.jbiomech.2018.08.028 . hal-01881658

\section{HAL Id: hal-01881658 \\ https://hal.science/hal-01881658}

Submitted on 10 Oct 2018

HAL is a multi-disciplinary open access archive for the deposit and dissemination of scientific research documents, whether they are published or not. The documents may come from teaching and research institutions in France or abroad, or from public or private research centers.
L'archive ouverte pluridisciplinaire HAL, est destinée au dépôt et à la diffusion de documents scientifiques de niveau recherche, publiés ou non, émanant des établissements d'enseignement et de recherche français ou étrangers, des laboratoires publics ou privés. 


\section{Articular-surface-based automatic anatomical coordinate systems for the knee bones.}

Submitted as a Short Communication

Authors:

Jean-Baptiste RENAULT ${ }^{\mathrm{a}, \mathrm{b},{ }^{*}}$

Gaëtan AÜLLO-RASSER ${ }^{a, b, d}$

Mathias DONNEZ ${ }^{\mathrm{a}, \mathrm{b}, \mathrm{c}}$

Sébastien PARRATTE ${ }^{a, b}$

Patrick CHABRAND ${ }^{\mathrm{a}, \mathrm{b}}$
Corresponding author:

Jean-Baptiste RENAULT

Address:

Institut des Sciences du Mouvement UMR 7287

Parc Scientifique et Technologique de Luminy

163 , avenue de Luminy

Case Postale 910

F-13288 Marseille Cedex 09 France

Phone number: +33491945242

Cellphone number: +33652136000

E-mail address: jean-baptiste.renault@univ-amu.fr

\section{Affiliations:}

a. Aix-Marseille University, CNRS, ISM UMR 7287, 13009 Marseille, France;

b. APHM, Institute for Locomotion, Department of orthopaedics and Traumatology, Sainte-Marguerite Hospital, 13009, Marseille, France

c. Newclip Technics, 44115 Haute-Goulaine, France

d. RLC Systèmes, Marseille, France

\section{Keywords:}

Anatomical coordinate system, Surgery planning, Kinematics, 3D imaging, 3D bone model

\section{Word Count}

2000 


\section{Abstract}

Increasing use of patient-specific surgical procedures in orthopaedics means that patient-specific anatomical coordinate systems (ACSs) need to be determined. For knee bones, automatic algorithms constructing ACSs exist and are assumed to be more reliable than manual methods, although both approaches are based on non-unique numerical reconstructions of true bone geometries. Furthermore, determining the best algorithms is difficult, as algorithms are evaluated on different datasets. Thus, in this study, we developed 3 algorithms, each with 3 variants, and compared them with 5 from the literature on a dataset comprising 24 lower-limb CT-scans. To evaluate algorithms' sensitivity to the operator-dependent reconstruction procedure, the tibia, patella and femur of each CT-scan were each reconstructed once by three different operators.

Our algorithms use principal inertia axis (PIA), cross-sectional area, surface normal orientation and curvature data to identify the bone region underneath articular surfaces (ASs). Then geometric primitives are fitted to ASs, and the ACSs are constructed from the geometric primitive points and/or axes. For each bone type, the algorithm displaying the least inter-operator variability is identified. The best femur algorithm fits a cylinder to posterior condyle ASs and a sphere to the femoral head, average axis deviations: $0.12^{\circ}$, position differences: $0.20 \mathrm{~mm}$. The best patella algorithm identifies the AS PIAs, average axis deviations: $0.91^{\circ}$, position differences: $0.19 \mathrm{~mm}$. The best tibia algorithm finds the ankle AS center and the $1^{\text {st }}$ PIA of a layer around a plane fitted to condyle ASs, average axis deviations: $0.38^{\circ}$, position differences: $0.27 \mathrm{~mm}$. 


\section{Introduction}

Progress in the treatment of knee articular pathologies has increased the use of 3D imaging. CT-scans are routinely used by clinicians for diagnostic purposes, surgery planning (Sariali et al. 2012) and patientspecific procedures (Leeuwen et al. 2015; Munier et al. 2017). Associated bone volumetric reconstructions make defining an anatomical coordinate system (ACS) mandatory.

Earlier ACS construction algorithms (Luo 2004; Wu et al. 2002) required manual selection of a small set of landmarks, which is operator-dependent (Victor et al. 2009). To average the errors made during landmark clicking, Fitzpatrick et al. (2007) and Cobb et al. (2008) clicked multiple points on each region of interest (ROI) and derived orientations and center from geometric primitive fitting, centroid or principal inertia axis (PIA) identifications. Kai et al. (2014), Miranda et al. (2010), Olender et al. (2014) and Ho et al. (2012) developed automatic ACS construction algorithms for the femur and tibia, Li et al. (2007) and Rainbow et al. (2013) for the patella, by automatizing ROI selection. However, there is no consensus on the ROls to select and on the geometries to fit them. No study takes for ROI the bone Articular Surfaces (AS) despite their importance in knee biomechanics. Moreover, although ACSs are constructed on bone models generated from manually segmented 3D images, no study has assessed the influence of this operator-dependent procedure. Our hypothesis is that restricting ROI to ASs makes ACS determination less sensitive to the procedure.

To test our hypothesis, we developed 3 algorithms (one per knee bone) that construct subject-specific ACSs by first identifying the ASs. For each of our algorithms, 3 variants are provided. 5 published algorithms were also implemented. All were evaluated on 24 CT-scans, each reconstructed once by 3 different operators. 


\section{Material \& Methods}

Bone geometry acquisitions and generations

24 CT-scans were retrieved from the Sainte-Marguerite Hospital database. The mid-diaphysis of long bones was not acquired (120KVp, knee window: $0.4-0.9 \times 0.4-0.9 \times 0.6 \mathrm{~mm}^{3}$, hip/ankle windows:

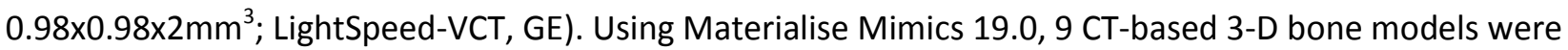
generated by CT-scan, 1 per operator and bone (Figure-1). For the segmentation, masks were created by global grey value thresholding followed by manual corrections when necessary. Reconstruction and smoothing parameters were chosen by each operator. Models were uniformly re-meshed with GMSH 2.16 (Marchandise et al. 2010).

\section{ACS overview}

Our algorithms aim at identifying continuous hole-free AS regions of the bone models. Each algorithm identifies the data (points, axes) required to construct an ACS. All geometry fittings are performed using the least-squares method. All algorithms were implemented in Matlab R2016a and available at https://github.com/renaultJB/GIBOC-Knee-Coordinate-System. Algorithms are further detailed in Appendix-A.

\section{Femoral ACS}

The 3 femur ACSs were defined by automatically detecting the femoral head and knee centers (FKC) and a condyle axis (Table-1). First, similar to Miranda et al. (2010), evolution of the cross-section area along the femur $1^{\text {st }}$ PIA (Gonzalez-Ochoa et al. 1998) allows the separation of the distal epiphysis, enabling its 3D convex hull to be determined. Given the epiphysis geometry, the largest edges of the 3D convex hull connect vertices located on the AS of the lateral condyle to vertices on the medial condyle. 
The femoral head center is identified using a two-iteration sphere fitting procedure. First, two regions around the most proximal and medial vertices of the proximal femur were represented by a sphere. Then, all the vertices located within $90 \%$ and $110 \%$ of the sphere radius are approximated by a new sphere, identifying the femoral head center (Figure-2.B).

\section{Condyle Ellipsoids (CE) variant}

The identified medial and lateral set of vertices are used to obtain all the condyle ASs, onto which two ellipsoids are fitted. The segment connecting their centers forms the condyle axis and the midpoint of this segment characterizes the FKC (Figure-2.B).

\section{Posterior Condyle Cylinder (PCC) variant}

From the ASs determined with the CE variant, only the parts posterior to the intercondylar fossa are kept, and selection of ASs is refined from surface normal orientation and curvature data. A cylinder is fitted to the posterior condyle ASs. FKC is the barycenter of the ASs projected onto the cylinder axis, which defines the condyle axis (Figure-2.B).

\section{Posterior Condyle Spheres (PCS) variant}

Identical to PCC, except two spheres are fitted instead of the cylinder. The segment connecting their centers forms the condyle axis and its midpoint the FKC (Figure-2.B).

\section{Ultimate step of femoral ACS Construction}

In each variant, the FKC is the ACS origin. The vector connecting the femoral head center to the FKC is

normalized to form the final $\overrightarrow{D P}$ vector. The condyle axis, made orthogonal to $\overrightarrow{D P}$, defines the final lateromedial vector $\overrightarrow{L M}$, and their cross product gives the final $\overrightarrow{A P}$ vector to form the ACS basis (Figure2.C). 


\section{Tibial ACS}

Three variants that automatically detect the tibial ankle and knee centers (FKC) and a condyle axis were developed (Table-2). Our algorithm begins by creating $\mathrm{ACS}_{0}$, a temporary ACS from PIA. On the distal tibia, AS elements are identified from normal orientations and curvature data. The ankle center is defined as the projection of the largest cross-section centroid onto the AS (Figure-3.B). On the proximal epiphysis, the tibial medial and lateral condyle ASs are identified with criteria based on surface curvature data, elements normal orientations and positions in $\mathrm{ACS}_{0}$.

\section{Condyle Articular Surface Centroids (CASC) variant}

The centroids of the medial and lateral ASs are identified and connected in a segment, whose midpoint and direction respectively define the TKC and the condyle axis (Figure-3.B).

\section{Ellipse on the Condyle Articular Surface Edges (ECASE) variant}

A plane, $\mathcal{P}_{\mathrm{AS}}$, is fitted to the combined ASs. The AS vertices are projected onto $\mathcal{P}_{\mathrm{AS}}$ and the $2 \mathrm{D}$ convex hull of this set of points is generated. Then, an ellipse is fitted to the convex hull vertices. The ellipse center and major axis respectively define the TKC and the condyle axis (Figure-3.B).

\section{Principal Inertia Axis of an Articular Surface Layer (PIAASL) variant}

The PIAASL variant identifies a bone layer centered on $\mathcal{P}_{\text {AS }}$ and between two planes parallel to $\mathcal{P}_{\text {AS }}$ (Figure-3.b). The layer $1^{\text {st }}$ PIA serves as the condyle axis, while its centroid, projected onto $\mathcal{P}_{\text {As, }}$ defines the TKC. 


\section{Ultimate step of tibial ACS Construction}

The condyle axis is made orthogonal to the final distaloproximal axis connecting the tibial ankle center to the TKC. These two axes plus the TKC define the final ACS (Figure-3.C).

\section{Patellar ACS}

The patella resembles a spherical cap, so its $3^{\text {rd }}$ PIA served as an initial AP axis (Figure-4.A). Its posterior face vertical ridge can define a distal to proximal (DP) axis. To identify an initial ridge orientation, we used the Rainbow et al. (2013) procedure. Briefly, it consists in finding the most posterior points of evenly separated cross-section outlines taken along the DP. Then the DP axis is iteratively reoriented, and the posterior points updated to minimize the standard deviation of their projection on an orthogonal ML axis.

\section{Volume ridge (VR) variant}

A non-linear regression is used to remove the points lying on the apex, and DP axis identification is repeated on the remaining points (Figure-4.B). The DP axis is then made orthogonal to the AP axis to define the ACS, the patella centroid being the patella center (PC) (Figure-4.C).

\section{Ridge Line (RL) variant}

Alternatively, a line is fitted on the ridge points and the AP axis is made orthogonal to it. The midpoint on the ridge defines the PC (Figure-4.C).

\section{Principal Inertia Axis of the Articular Surface (PIAAS) variant}

The AS is identified as the elements within the ridge DP range, using criteria based on the normal orientation relative to the ridge line. The AS PIAs serve as ML, DP and AP axes, while the centroid of the AS completes the definition of the ACS (Figure-4.C). 


\section{Data analysis}

To evaluate the inter-operator variability of each developed and implemented algorithm (Kai et al. 2014, Miranda et al. 2010 and Rainbow et al. 2013), a global variability angle (GVA) was computed along with per-subject mean $(\overline{A D})$ and across-subject maximal $(m A D)$ paired axis deviations.

For GVA all ACS basis were transformed to unit quaternions and the mean quaternion (Markley et al. 2007) $\boldsymbol{q}_{i, b, a}^{\text {mean }}$ per subject, bone and algorithm variant was calculated. GVA quantifies the global deviation of each operator's ACS relative to the mean ACS, and is defined by:

$$
\begin{gathered}
(a, b) \in\{(P C C, \text { Femur }), . .(\text { VR }, \text { Patella }), .,(\text { Kai et al.2014, Tibia })\} \\
i \in \llbracket 1,2,3, \ldots, 23,24 \rrbracket
\end{gathered} G_{i, b, a}=\frac{1}{3} \sum_{1 \leq k_{1} \leq 3} 2 \cdot \cos ^{-1}\left(\boldsymbol{q}_{i, b, a}^{k_{1}} \cdot \boldsymbol{q}_{i, b, a}^{\text {mean }}\right)
$$

$\overline{A D}$ and $m A D$ quantify the axis deviations between pairs of operators $\left(k_{1}\right.$ and $\left.k_{2}\right)$, and are defined by:

$$
\forall(\zeta, \vec{V}) \in\{(\alpha, \overrightarrow{A P}),(\beta, \overrightarrow{L M}),(\gamma, \overrightarrow{D P})\}, \quad\left\{\begin{array}{l}
\zeta_{i, b, a}^{\overline{A D}}=\frac{1}{3} \sum_{\substack{1 \leq k_{1}<k_{2} \leq 3\\
}} \operatorname{angle}\left(\overrightarrow{V_{l, b, a, k_{1}}}, \overrightarrow{V_{l, b, a, k_{2}}}\right) \\
\zeta_{b, a}^{m A D}=\max _{\substack{1 \leq i \leq 24 \\
1 \leq k_{1}<k_{2} \leq 3}} \operatorname{angle}\left(\overrightarrow{V_{l, b, a, k_{1}}}, \overrightarrow{V_{l, b, a, k_{2}}}\right)
\end{array}\right.
$$

Repeatability of origin determination was evaluated with the radii of the minimal bounding sphere $(B S R)$ enclosing the 3 different origins determined for each subject's bones.

We performed two Kruskal-Wallis tests in $\mathbf{R}$ ( $\mathrm{R}$ Core Team 2017) on GVA and BSR, to assess whether the algorithms' ACSs were equal. Pairwise algorithm differences were evaluated via a post hoc Dunn's test (Dinno 2017).

\section{Results}

All algorithms successfully performed ACS constructions on their corresponding 72 bone models. Full results are presented in Table- 3 and Table-4, the major points being as follows. 
For the femur, mean algorithm GVAs ranged from $0.08^{\circ}$ to $0.39^{\circ}$, with PCC GVA significantly lower than all the others. This translates into lower mean $\left(0.12^{\circ}\right)$ and maximal axis deviations $\left(0.66^{\circ}\right)$ for alpha and beta angle of PCC, as well as the lowest maximal BSR $(0.44 \mathrm{~mm})$. Algorithm BSRs did not differ significantly.

For the patella, PIAAS mean and maximal axis deviations were between $0.01^{\circ}$ and $1.20^{\circ}$ lower than those of other algorithms, and its GVA was significantly lower than Rainbow et al. (2013) GVA. The VR and Rainbow et al. (2013) algorithm BSRs were identical and significantly lower than the others.

For the tibia, Kai et al. (2014) and PIAASL had comparable GVAs and BSRs, significantly lower than with other algorithms. PIAASL had the lowest mean $\left(0.05^{\circ}\right.$ to $\left.0.39^{\circ}\right)$ and maximal $\left(0.27^{\circ}\right.$ to $\left.1.51^{\circ}\right)$ axis deviations.

\section{Discussion}

We present 3 new automatic algorithms that construct subject-specific ACSs on 3D models of the femur, patella and tibia, and also provide three variants on each algorithm. Together with 5 published algorithms, these were implemented and assessed on 24 subjects. ACSs were not compared among subjects, as we cannot discriminate the effect of the algorithm from the subjects' morphological differences; however, we compared ACSs constructed from the same bones but reconstructed by 3 different operators.

From our results, no algorithm stands out as superior on all criteria (Table-5). However, taking average position (in $\mathrm{mm}$ ) and orientation variability as equally important (in ${ }^{\circ}$ ), the best algorithm variants for the femur, patella and tibia are, respectively, PCC, PIAAS and PIAASL. 
Our main contributions are the automatic identification of AS ROIs, and the first assessment of ACS algorithm sensitivity to operator-dependent bone reconstructions. We show that restricting ROI to AS makes ACS less operator-dependent, our best algorithm variants providing submillimeter and sub-degree variability, lower than the published algorithms we implemented (Kai et al. 2014; Miranda et al. 2010; Rainbow et al. 2013). Two AS characteristics could explain this result. The subchondral bone high x-rays absorption makes ASs less prone to manual correction during segmentation and their smooth geometry limits their sensitivity to reconstruction parameters. We also compared our femur and tibia results to manual method results. Our mean inter-operator axis deviations were 10 to $75 \%$ lower than those of Victor et al. (2009), who evaluated the variability of axes derived from manually selected landmarks. Additionally, the GVA means of our best tibial and femoral algorithm variants were over 8 times lower than those of Schlatterer et al. (2009).

Overall, our findings demonstrate the importance of the choice of both ROI and associated geometries or data. Tibial algorithms based only on identified condyle surfaces display high variability, while those using a larger set of elements yield superior results. To fit the posterior condyle ASs on the femur, considering a cylinder as in Eckhoff et al. (2007), instead of two spheres, significantly improved reliability.

Our algorithms allow the definition of the 3 anatomic planes, the first step towards intra-bone measurements, surgical planning and knee kinematic assessment. Using these ACSs, we aim in a future study to identify the planned-vs-achieved position of total knee replacement components.

\section{Conflict of interest statement}

None. 


\section{Acknowledgements}

Work and English revision (Marjorie SWEETKO) funded by Aix-Marseille University.

Appendix-A. Supplementary information

Supplementary information associated with this article can be found in ... 
Cobb, J.P. et al., 2008. The anatomical tibial axis: RELIABLE ROTATIONAL ORIENTATION IN KNEE REPLACEMENT. Journal of Bone and Joint Surgery - British Volume, 90-B(8), pp.1032-1038.

Dinno, A., 2017. dunn.test: Dunn's Test of Multiple Comparisons Using Rank Sums.

Eckhoff, D. et al., 2007. An ABJS best paper: Difference between the epicondylar and cylindrical axis of the knee. In Clinical Orthopaedics and Related Research. pp. 238-244.

Fitzpatrick, C. et al., 2007. A tibial-based coordinate system for three-dimensional data. Knee, 14(2), pp.133-137.

Gonzalez-Ochoa, C., McCammon, S. \& Peters, J., 1998. Computing moments of objects enclosed by piecewise polynomial surfaces. ACM Transactions on Graphics, 17(3), pp.143-157.

Ho, K.C.T. et al., 2012. Computed tomography analysis of knee pose and geometry before and after total knee arthroplasty. Journal of Biomechanics, 45(13), pp.2215-2221.

Kai, S. et al., 2014. Automatic construction of an anatomical coordinate system for three-dimensional bone models of the lower extremities - Pelvis, femur, and tibia. Journal of Biomechanics, 47(5), pp.1229-1233.

Leeuwen, J.A.M.J. van et al., 2015. Comparison of planned and achieved implant position in total knee arthroplasty with patient-specific positioning guides. Acta orthopaedica, 86(2), pp.201-207.

$\mathrm{Li}, \mathrm{G}$. et al., 2007. The coupled motion of the femur and patella during in vivo weightbearing knee flexion. Journal of biomechanical engineering, 129(6), pp.937-43.

Luo, C.F., 2004. Reference axes for reconstruction of the knee. Knee, 11(4), pp.251-257.

Marchandise, E. et al., 2010. Quality meshing based on STL triangulations for biomedical simulations. International Journal for Numerical Methods in Biomedical Engineering, 26(7), pp.876-889.

Markley, F.L. et al., 2007. Averaging Quaternions. Journal of Guidance, Control, and Dynamics, 30(4), pp.1193-1197.

Miranda, D.L. et al., 2010. Automatic determination of anatomical coordinate systems for threedimensional bone models of the isolated human knee. Journal of Biomechanics, 43(8), pp.16231626.

Munier, M. et al., 2017. Can three-dimensional patient-specific cutting guides be used to achieve optimal correction for high tibial osteotomy? Pilot study. Orthopaedics and Traumatology: Surgery and Research, 103(2), pp.245-250.

Olender, G. et al., 2014. Validation of an Anatomical Coordinate System for Clinical Evaluation of the Knee Joint in Upright and Closed MRI. Annals of Biomedical Engineering, 42(5), pp.1133-1142.

R Core Team, 2017. R: A Language and Environment for Statistical Computing.

Rainbow, M.J. et al., 2013. Automatic determination of an anatomical coordinate system for a threedimensional model of the human patella. Journal of Biomechanics, 46(12), pp.2093-2096.

Sariali, E. et al., 2012. Accuracy of the preoperative planning for cementless total hip arthroplasty. A randomised comparison between three-dimensional computerised planning and conventional templating. Orthopaedics and Traumatology: Surgery and Research, 98(2), pp.151-158. 
Schlatterer, B. et al., 2009. Skeletal landmarks for TKR implantations: evaluation of their accuracy using EOS imaging acquisition system. Orthopaedics \& traumatology, surgery \& research : OTSR, 95(1), pp.2-11.

Victor, J. et al., 2009. How precise can bony landmarks be determined on a CT scan of the knee? Knee, 16(5), pp.358-365.

$\mathrm{Wu}, \mathrm{G}$. et al., 2002. ISB recommendation on definitions of joint coordinate system of various joints for the reporting of human joint motion-part I: ankle, hip, and spine. Journal of Biomechanics, 35(4), pp.543-548. 


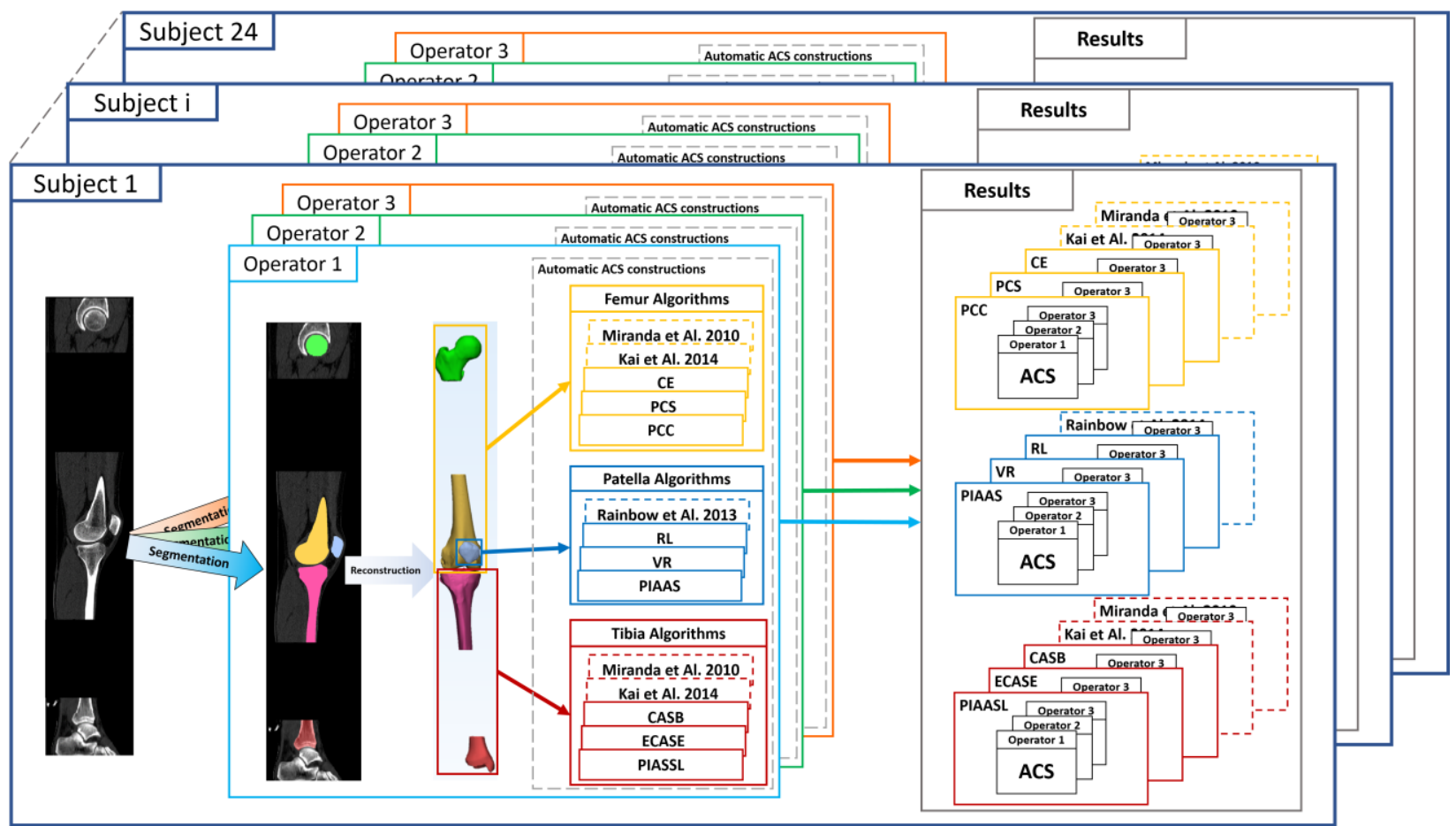

Figure-1. Workflow of the methods applied to the 24 subjects. For each subject, 3 operators independently segmented the CT-

scan once. Then each operator reconstructed the 3 knee bones from his own segmentation, yielding 3 bone models per operator.

The tibia and femur bone models were composed of two parts, proximal and distal, because the mid-diaphysis of long bone was not acquired during the imaging procedure. Next, the bone models were re-meshed using GMSH to obtain a surface of uniform triangles (target edge length $=0.5 \mathrm{~mm}$ ). Then, femur algorithms were applied to the femur model to automatically construct 5 anatomic coordinate systems (ACSs), one per variant. The same procedure was applied to the patella and tibia. In the automatic ACS constructions section, plain lines correspond to the developed 3 variants of each of our algorithms while dashed lines are for the algorithms we implemented from the literature. Finally, the ACSs constructed on the bone models were pooled by algorithm and variants in the results section for each subject for later comparison. 


\begin{tabular}{|c|c|c|c|}
\hline Variant Label & CE & PCS & PCC \\
\hline Variant Full Name & Condyle Ellipsoids & Posterior Condyle Spheres & Posterior Condyle Cylinder \\
\hline Femoral head Center & \multicolumn{2}{|c|}{ Center of a sphere fitted on the femoral head } \\
\hline Condyle ASs & Whole distal femur ASs & \multicolumn{2}{|c|}{ Medial and lateral posterior condyle ASs } \\
\hline Associated primitives & Two ellipsoids & Two spheres & One cylinder \\
\hline Axis of the condyles & $\begin{array}{c}\text { Line connecting the } \\
\text { ellipsoid centers }\end{array}$ & $\begin{array}{c}\text { Line connecting the sphere } \\
\text { centers }\end{array}$ & $\begin{array}{c}\text { Centroid of the ASs } \\
\text { projected onto the Cylinder } \\
\text { Axis }\end{array}$ \\
\hline $\begin{array}{c}\text { Femoral knee center } \\
\text { (ACS origin) }\end{array}$ & $\begin{array}{c}\text { Midpoint between the } \\
\text { ellipsoid centers }\end{array}$ & $\begin{array}{c}\text { Midpoint between the } \\
\text { sphere centers }\end{array}$ \\
\hline
\end{tabular}

Table-1. Names and brief descriptions of the 3 variants of our algorithm constructing ACSs for the femur. 


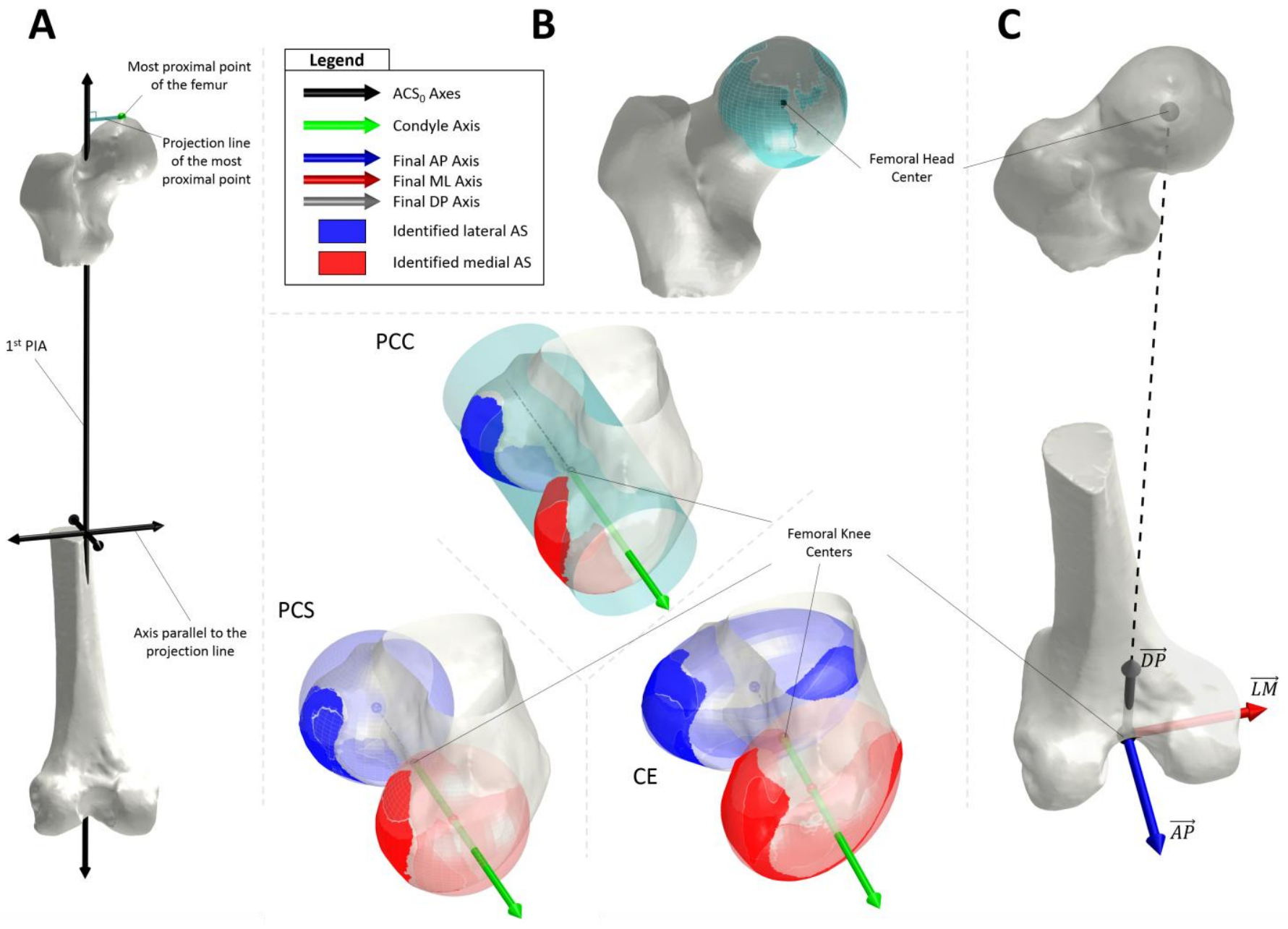

Figure-2. Illustrations of the main steps and features of the 3 algorithm variants we developed to construct an anatomical coordinate system on the femur. (A) Initial coordinate system constructed using the first principal inertia axis and the top of the femoral head. (B) Top: identification of the femoral head center. Bottom: visual representation of the features of the 3 variants identifying the femoral condyle axis from automatically selected articular surface elements and their different associated geometric primitives. (C) Example of the generic construction of the final right-handed orthogonal ACSs, the procedure for constructing the final ACS from the condyle axis and the axis connecting the femoral knee and head centers is common to all variants. See text and Table-1 for explanation of the acronyms. 


\begin{tabular}{|c|c|c|c|}
\hline Variant Label & CASC & ECASE & PIAASL \\
\hline Variant Full name & $\begin{array}{l}\text { Condyle Articular } \\
\text { Surface Centroids }\end{array}$ & $\begin{array}{l}\text { Ellipse on Condyle } \\
\text { Articular Surface Edges }\end{array}$ & $\begin{array}{l}\text { Principal Inertia Axes of } \\
\text { Articular Surface Layer }\end{array}$ \\
\hline $\begin{array}{l}\text { Tibial Ankle } \\
\text { Center }\end{array}$ & \multicolumn{3}{|c|}{$\begin{array}{l}\text { Centroid of the largest section of the distal tibia projected onto the distal } \\
\text { tibia AS }\end{array}$} \\
\hline Condyle ASs & \multicolumn{3}{|c|}{ Two AS regions on the medial and lateral condyles } \\
\hline $\begin{array}{l}\text { Associated } \\
\text { primitives }\end{array}$ & & A plane then an ellipse & A plane \\
\hline $\begin{array}{l}\text { Axis of the } \\
\text { condyles }\end{array}$ & $\begin{array}{l}\text { Line connecting the } \\
\text { centroids of the } \\
\text { medial and lateral } \\
\text { ASs }\end{array}$ & $\begin{array}{l}\text { Major axis of the } \\
\text { ellipse associated with } \\
\text { the medial and lateral } \\
\text { borders of the ASs }\end{array}$ & $\begin{array}{l}1^{\text {st }} \text { PIA of a layer of the } \\
\text { tibia around the plane }\end{array}$ \\
\hline $\begin{array}{l}\text { Tibial knee center } \\
\text { (ACS origin) }\end{array}$ & $\begin{array}{l}\text { Midpoint between } \\
\text { the centroids }\end{array}$ & Center of the ellipse & $\begin{array}{l}\text { Centroid of the layer } \\
\text { projected onto the } \\
\text { plane }\end{array}$ \\
\hline
\end{tabular}

Table-2. Names and brief description of the 3 variants of our algorithm constructing an ACS on the tibia. 
A

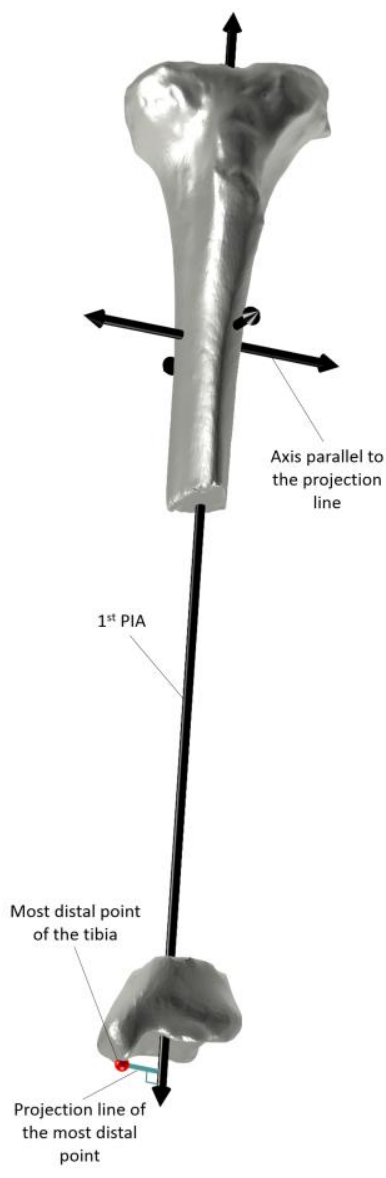

B

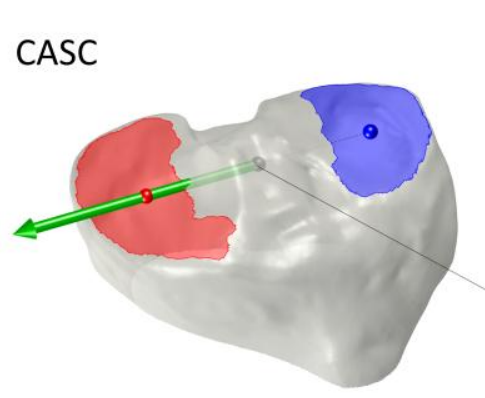

C

\section{ECASE}
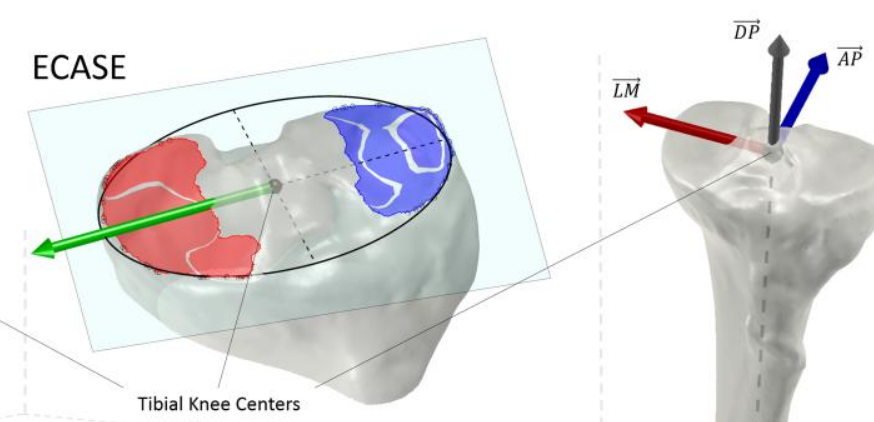

Tibial Knee Centers

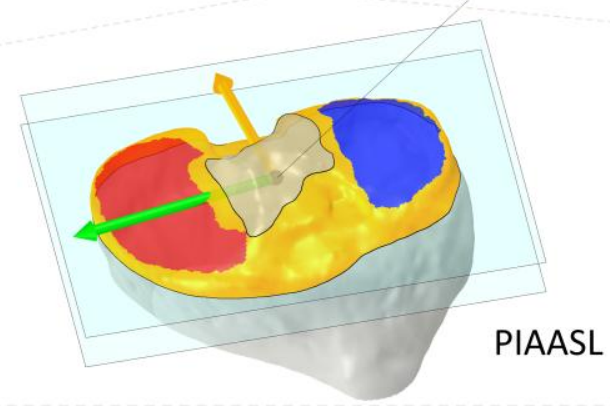

PIAASL
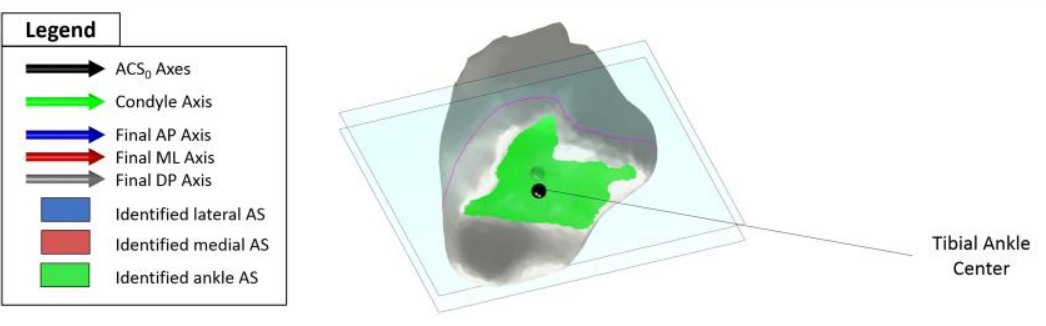

Figure-3. Illustrations of the main steps and features of the 3 variants of the algorithm that constructs an anatomical coordinate system on the tibia. (A) Initial coordinate system constructed using the first principal inertia axis and the summit of the medial malleolus. (B) Top: visual representations of the different approaches used by the 3 variants to identify the tibial condyle axis, showing important construction features specific to each method. Bottom: identification of the tibial ankle center. (C) Construction of the final right-handed orthogonal ACSs, the procedure for constructing the final ACS from the condyle axis and the axis connecting the tibial ankle and knee centers is common to all algorithms. See text and Table-2 for explanation of the acronyms. 


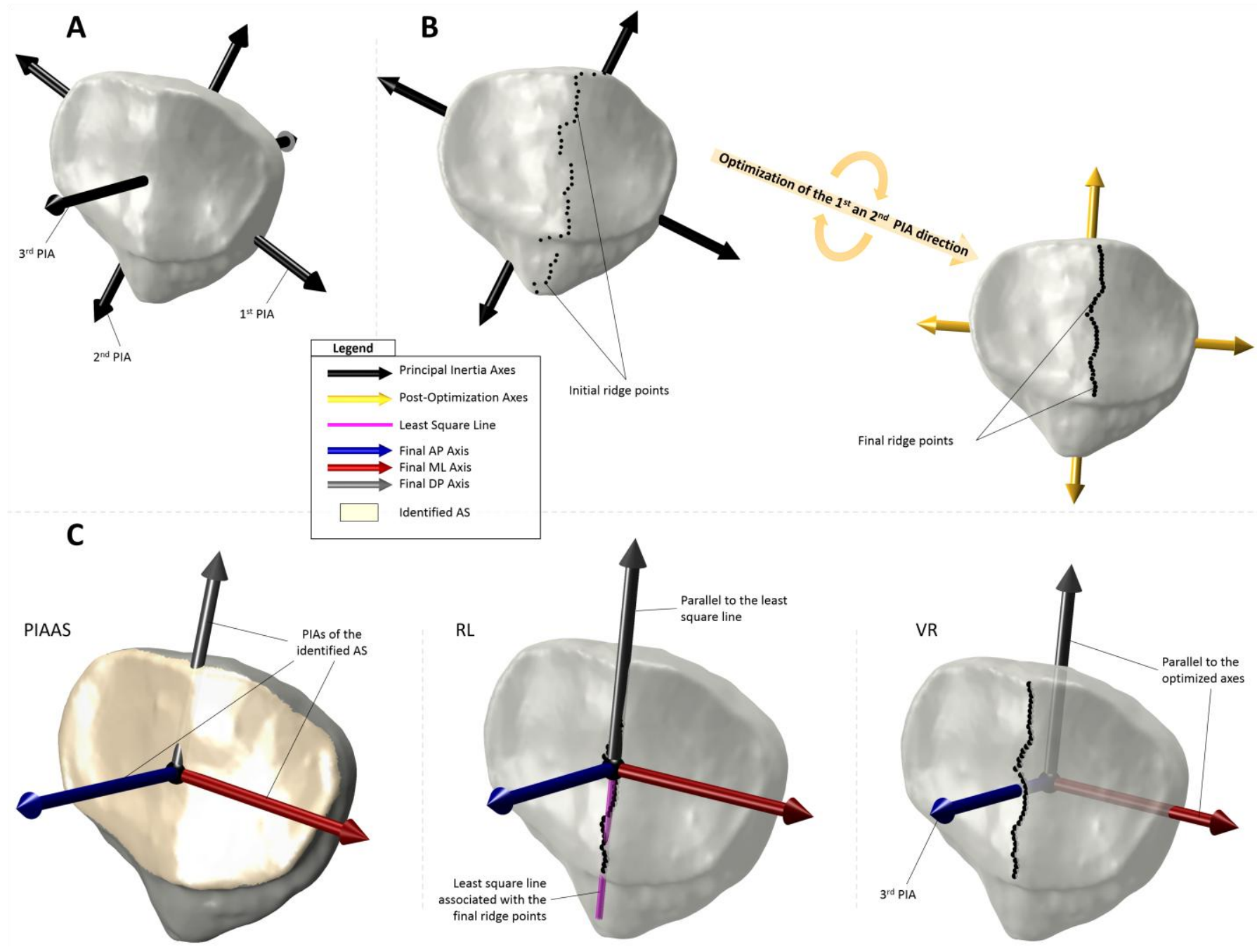

Figure-4. Illustrations of the main steps and features of the 3 variants of the algorithm that constructs a ACS on the patella. (A) Principal inertia axis of the whole patella. (B) Optimization procedure to identify the vertical ridge on the patella AS. (C) Brief description of the construction of the ACS for each variant. See text for explanation of the acronyms. 


\begin{tabular}{|c|c|c|c|c|c|c|}
\hline & \multirow[b]{3}{*}{ Methods } & \multicolumn{2}{|l|}{$\begin{array}{c}\text { Global } \\
\text { Variability }\end{array}$} & \multicolumn{2}{|c|}{ Axis Deviations $\left[{ }^{\circ}\right]$} & \multirow[t]{2}{*}{ BSR $[\mathrm{mm}]$} \\
\hline & & Angle $\left[{ }^{\circ}\right]: G V A$ & Alpha $(\overrightarrow{A P})$ & Beta $(\overrightarrow{L M})$ & Gamma $(\overrightarrow{D P})$ & \\
\hline & & $\begin{array}{l}\operatorname{mean}(\mathrm{SD}) \\
\max \end{array}$ & $\begin{array}{l}\overline{A D} \text { mean }(\mathrm{SD}) \\
m A D\end{array}$ & $\begin{array}{l}\overline{A D} \text { mean }(\mathrm{SD}) \\
m A D\end{array}$ & $\begin{array}{l}\overline{A D} \text { mean }(\mathrm{SD}) \\
m A D\end{array}$ & $\begin{array}{l}\operatorname{mean}(\mathrm{SD}) \\
\max \end{array}$ \\
\hline \multirow{6}{*}{$\sum_{\text {号 }}^{\stackrel{\varrho}{丂}}$} & PCC & $0,08(0,05)$ & $0,12(0,09)$ & $0,12(0,08)$ & $0,06(0,03)$ & $0,20(0,11)$ \\
\hline & & 0,26 & 0,66 & 0,65 & 0,15 & 0,44 \\
\hline & PCS & $\begin{array}{ll}0,15 & (0,15) \\
0,63 & \end{array}$ & $\begin{array}{ll}0,25 & (0,24) \\
1,58 & \end{array}$ & $\begin{array}{l}0,25 \quad(0,25) \\
1,58\end{array}$ & $\begin{array}{l}0,05 \quad(0,03) \\
0,15\end{array}$ & $\begin{array}{ll}0,17 & (0,12) \\
0,61 & \end{array}$ \\
\hline & CE & $\begin{array}{l}0,16 \quad(0,16) \\
0,80\end{array}$ & $\begin{array}{l}0,27 \quad(0,24) \\
1,50\end{array}$ & $\begin{array}{l}0,27 \quad(0,25) \\
1,82\end{array}$ & $\begin{array}{l}0,05 \quad(0,04) \\
0,25\end{array}$ & $\begin{array}{l}0,18 \quad(0,26) \\
1,35\end{array}$ \\
\hline & $\begin{array}{c}\text { Kai } \\
\text { et al. } 2014\end{array}$ & $\begin{array}{ll}0,19 & (0,14) \\
0,69 & \end{array}$ & $\begin{array}{l}0,28 \quad(0,19) \\
1,18\end{array}$ & $\begin{array}{l}0,27 \quad(0,23) \\
1,64\end{array}$ & $\begin{array}{l}0,18 \quad(0,20) \\
1,19\end{array}$ & $\begin{array}{l}0,16(0,14) \\
0,67\end{array}$ \\
\hline & $\begin{array}{l}\text { Miranda } \\
\text { et al. } 2010\end{array}$ & $\begin{array}{ll}0,39 & (0,13) \\
0,62 & \end{array}$ & $\begin{array}{l}0,50 \quad(0,25) \\
1,50\end{array}$ & $\begin{array}{l}0,66(0,21) \\
1,51\end{array}$ & $\begin{array}{l}0,38 \quad(0,13) \\
0,96\end{array}$ & $\begin{array}{ll}0,29 & (0,15) \\
0,63 & \end{array}$ \\
\hline \multirow{5}{*}{ 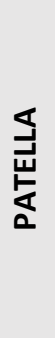 } & PIAAS & $0,57(0,25)$ & $0,35(0,17)$ & $0,93(0,41)$ & $0,90 \quad(0,42)$ & $0,19(0,10)$ \\
\hline & & 1,15 & 0,86 & 2,65 & 2,65 & 0,43 \\
\hline & $\mathrm{RL}$ & $\begin{array}{ll}0,72 & (0,42) \\
1,83 & \end{array}$ & $\begin{array}{l}0,36 \quad(0,24) \\
1,22\end{array}$ & $\begin{array}{l}1,21 \quad(0,79) \\
5,09\end{array}$ & $\begin{array}{l}1,22(0,79) \\
5,09\end{array}$ & $\begin{array}{l}0,45 \quad(0,35) \\
1,69\end{array}$ \\
\hline & VR & $\begin{array}{l}0,74 \quad(0,43) \\
1,82\end{array}$ & $\begin{array}{l}0,40 \quad(0,26) \\
1,62\end{array}$ & $\begin{array}{l}1,21(0,79) \\
5,09\end{array}$ & $\begin{array}{l}1,26(0,81) \\
5,12\end{array}$ & $\begin{array}{l}0,08 \quad(0,06) \\
0,27\end{array}$ \\
\hline & $\begin{array}{l}\text { Rainbow } \\
\text { et al. } 2013\end{array}$ & $\begin{array}{l}1,18 \quad(1,37) \\
1,82\end{array}$ & $\begin{array}{l}0,40 \quad(0,26) \\
1,62\end{array}$ & $\begin{array}{l}1,21(0,79) \\
20,49\end{array}$ & $\begin{array}{l}1,26(0,81) \\
20,48\end{array}$ & $\begin{array}{ll}0,08 & (0,06) \\
0,27 & \end{array}$ \\
\hline \multirow{5}{*}{ 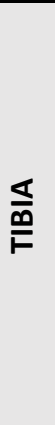 } & PIAASL & $\begin{array}{ll}0,23 & (0,15) \\
0,56 & \end{array}$ & $\begin{array}{ll}0,39 & (0,27) \\
1,51 & \end{array}$ & $\begin{array}{l}0,39(0,26) \\
1,51\end{array}$ & $\begin{array}{ll}0,05 & (0,04) \\
0,27 & \end{array}$ & $\begin{array}{ll}0,25 & (0,14) \\
0,73 & \end{array}$ \\
\hline & ECASE & $\begin{array}{ll}0,68 & (0,74) \\
3,83 & \end{array}$ & $\begin{array}{l}1,14 \quad(1,10) \\
8,68\end{array}$ & $\begin{array}{l}1,12(1,10) \\
8,67\end{array}$ & $\begin{array}{ll}0,27 & (0,18) \\
1,26 & \end{array}$ & $\begin{array}{ll}0,51 & (0,40) \\
1,98 & \end{array}$ \\
\hline & CASC & $\begin{array}{ll}0,83 & (0,53) \\
2,30\end{array}$ & $\begin{array}{l}1,42 \quad(0,95) \\
6,47\end{array}$ & $\begin{array}{l}1,40(0,96) \\
6,47\end{array}$ & $\begin{array}{l}0,25 \quad(0,14) \\
1,13\end{array}$ & $\begin{array}{ll}0,47 & (0,26) \\
1,23 & \end{array}$ \\
\hline & $\begin{array}{c}\text { Kai } \\
\text { et al. } 2014\end{array}$ & $\begin{array}{l}0,26 \quad(0,29) \\
1,19\end{array}$ & $\begin{array}{ll}0,41 & (0,48) \\
2,85 & \end{array}$ & $\begin{array}{l}0,42(0,48) \\
2,85\end{array}$ & $\begin{array}{l}0,05 \quad(0,06) \\
0,49\end{array}$ & $\begin{array}{ll}0,27 & (0,21) \\
0,70\end{array}$ \\
\hline & $\begin{array}{l}\text { Miranda } \\
\text { et al. } 2010\end{array}$ & $\begin{array}{l}0,35 \quad(0,19) \\
0,82\end{array}$ & $\begin{array}{l}0,58 \quad(0,31) \\
1,94\end{array}$ & $\begin{array}{l}0,56(0,29) \\
1,93\end{array}$ & $\begin{array}{l}0,17 \quad(0,23) \\
1,75\end{array}$ & $\begin{array}{ll}0,30 & (0,18) \\
0,81 & \end{array}$ \\
\hline
\end{tabular}

Table-3. Overall results, for each bone type and all developed and implemented algorithms, showing Global Variability Angles, Axis Deviations and Radius of minimal bounding sphere for all subjects. 


\begin{tabular}{|c|c|c|c|c|c|c|c|c|c|c|c|}
\hline & \multirow[b]{2}{*}{$p$-values } & \multicolumn{5}{|c|}{ GVA } & \multicolumn{5}{|c|}{ BSR } \\
\hline & & \multicolumn{5}{|c|}{ Algorithms } & \multicolumn{5}{|c|}{ Algorithms } \\
\hline & vs & PCC & PCS & $\mathrm{CE}$ & Kai & Miranda & PCC & PCS & CE & Kai & Miranda \\
\hline \multirow{6}{*}{$\underset{\text { 嵌 }}{\stackrel{\Upsilon}{\supset}}$} & PCC & & $0,008 * *$ & $0,003^{* *}$ & $0 * * *$ & $0 * * *$ & & $0,01 * *$ & $0,015^{*}$ & $0,029 *$ & $0,023^{*}$ \\
\hline & PCS & $0,008 * *$ & & 0,36 & 0,12 & $0 * * *$ & $0,01^{* *}$ & & 0,19 & 0,27 & $0 * * *$ \\
\hline & CE & $0,003 * *$ & 0,36 & & 0,21 & $0 * * *$ & $0,015^{*}$ & 0,19 & & 0,39 & $0 * * *$ \\
\hline & Kai et al. 2014 & $0 * * *$ & 0,12 & 0,21 & & $0 * * *$ & $0,029 *$ & 0,27 & 0,3953 & & $0 * * *$ \\
\hline & Miranda et al. 2010 & $0 * * *$ & $0 * * *$ & $0 * * *$ & $0 * * *$ & & $0,023^{*}$ & $0 * * *$ & $0 * * *$ & $0 * * *$ & \\
\hline & VS & PIAAS & $\mathrm{RL}$ & & $R$ & Rainbow & PIAAS & $\mathrm{RL}$ & & VR & Rainbow \\
\hline \multirow{5}{*}{ 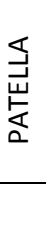 } & PIAAS & & 0,1 & & 12 & $0,013^{*}$ & & 0,008 & & $* * *$ & $0 * * *$ \\
\hline & $\mathrm{RL}$ & 0,14 & & & & 0,13 & $0,008 * *$ & & & $* * *$ & $0 * * *$ \\
\hline & VR & 0,12 & 0,4 & & & 0,15 & $0 * * *$ & $0 * *$ & & & 0,5 \\
\hline & Rainbow et al. 2013 & $0,013^{*}$ & 0,1 & & 15 & & $0 * * *$ & $0 * *$ & &, 5 & \\
\hline & VS & PIAASL & ECASE & CASC & Kai & Miranda & PIAASL & ECASE & CASC & Kai & Miranda \\
\hline \multirow{5}{*}{ 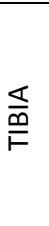 } & PIAASL & & $0 * * *$ & $0 * * *$ & 0,38 & $0,03 *$ & & 0,006 & $0 * * *$ & 0,49 & 0,13 \\
\hline & ECASE & $0 * * *$ & & 0,14 & $0 * * *$ & $0,01 * *$ & 0,006 & & 0,41 & $0 * * *$ & $0,017^{*}$ \\
\hline & CASC & $0 * * *$ & 0,14 & & $0 * * *$ & $0 * * *$ & $0 * * *$ & 0,4146 & & $0 * * *$ & $0,01 * *$ \\
\hline & Kai et al. 2014 & 0,38 & $0 * * *$ & $0 * * *$ & & $0,01^{*}$ & 0,49 & $0 * * *$ & $0 * * *$ & & 0,12 \\
\hline & Miranda et al. 2010 & $0,03 *$ & $0,01 * *$ & $0 * * *$ & $0,01 *$ & & 0,13 & $0,017^{*}$ & $0,01^{* *}$ & 0,12 & \\
\hline
\end{tabular}

Table-4. Paired comparisons of the different algorithms and variants with a Post hoc Dunn's test for Global Variability Angle

(GVA) and Bounding Sphere Radius (BSR) results. Paired comparisons of the algorithms permit their ranking. $\left(^{*}: p<0.05 ; * *: p\right.$

$<0.01 * * *: p<0.001) . p$-Values lower than 0.0001 are displayed as 0 in this table.

\begin{tabular}{|c|c|c|c|c|}
\hline & $\begin{array}{c}\text { Average global } \\
\text { orientation variability }\end{array}$ & $\begin{array}{c}\text { Maximal orientation } \\
\text { differences between } \\
\text { two operators for all } \\
\text { subject }\end{array}$ & $\begin{array}{c}\text { Average origin } \\
\text { positions variability }\end{array}$ & $\begin{array}{l}\text { Maximal origin } \\
\text { positions variability } \\
\text { for all subjects }\end{array}$ \\
\hline Patella & PIAAS & PIAAS & $\begin{array}{l}\text { VR \& Rainbow et al. } \\
2013\end{array}$ & $\begin{array}{l}\text { VR \& Rainbow et al. } \\
2013\end{array}$ \\
\hline Tibia & PIAASL & PIAASL & PIAASL & Kai et al. 2014 \\
\hline
\end{tabular}

Table-5. Presentation of the algorithms displaying the lowest inter-operator variability according to different criteria for each 